\title{
Clinical trial of methysergide and other preparations in the management of migraine
}

\author{
D. A. CURRAN ${ }^{1}$ AND J. W. LANCE \\ From the Division of Neurology, the Prince Henry Hospital, Sydney, and \\ the School of Medicine, University of New South Wales
}

The treatment of migraine has been bedevilled by the multitude of drugs which improve the condition and the lack of any which cure it. This situation indicates the considerable knowledge acquired about factors contributing to the migraine attack, without the formation of any firm concept of the underlying disturbance.

It is now well accepted that the extracranial blood vessels undergo phases of constriction, dilatation, and possibly fixation of the vessel wall by oedema as a part of the migraine attack (Tunis and Wolff, 1952; Wolff, 1955; Lund, 1957). The most likely explanation of transient paraesthesiae, aphasia, or hemiparesis in migraine is constriction of the middle cerebral artery and its branches. Fortification spectra (turret-shaped or zig-zag hallucinations of light and colour) are probably the result of changes in the posterior cerebral artery supplying the visual cortex, and slow waves may appear in the E.E.G. tracing from the appropriate posterior quadrant. Unformed flashes of light indicate spasm of the ophthalmic artery if they are restricted to the field of one eye, or of the posterior cerebral artery if they occupy homonymous half-fields. Constriction of the basilar artery may contribute brain-stem symptoms of tinnitus, vertigo, dysarthria, dyscoordination, ataxia, or loss of consciousness (Bickerstaff, 1961a, b). Fluid retention is common at the time of the migraine headache (Schottstaedt and Wolff, 1955), but prevention of fluid accumulation by diuretics does not influence the onset of the headache (Ostfeld, Reis, Goodell, and Wolff, 1955). The pain of the headache is consequent upon dilatation of extracranial vessels and the presence of chemical substances around the vessel, producing a sterile inflammatory reaction (Chapman, Ramos, Goodell, Silverman, and Wolff, 1960). Nausea and vomiting are the usual accompaniments of migraine and diarrhoea is not uncommon.

The search for a humoral agent which could constrict and dilate blood vessels, produce oliguria, and stimulate the gut led to consideration of 'Sandoz research fellow in neurology. 5-hydroxytryptamine (serotonin) as a possible mediator of the migraine syndrome. Sicuteri, Testi, and Anselmi (1961) showed that 24-hour excretion of urinary hydroxy indoles (which include 5-hydroxyindoleacetic acid, 5HIAA, the chief breakdown product of serotonin) was increased during the migraine attack. Preliminary observations of our own have confirmed that 5HIAA excretion increases with the onset of migraine and that this change precedes the onset of vomiting. Ostfeld, Chapman, Goodell, and Wolff (1957) claimed that a headache similar to migraine could be produced by periarterial injection of serotonin, but this has since been denied by Kimball, Friedman, and Vallejo (1960). These authors could not find any significant change in plasma serotonin levels during the migraine attack, but showed that the headache could be relieved by the injection of $5 \mathrm{mg}$. of serotonin intravenously. The concentration of serotonin in the cerebrospinal fluid is not altered in migraine (Southren and Christoff, 1962). It is known that the administration of reserpine will denude blood platelets of their serotonin content (Haverback, Dutcher, Shore, Tomich, Terry, and Brodie, 1957) and yet the long-term administration of reserpine has no significant effect on the frequency of migraine attacks (Friedman, 1955). However, the injection of $2.5 \mathrm{mg}$. reserpine will precipitate a migraine-type headache in a susceptible subject, which can be relieved by the injection of 5-hydroxytryptophane, the precursor of serotonin (Kimball et al., 1960).

In spite of the lack of definite evidence implicating serotonin in the causation of migraine, a serotonin antagonist, methysergide, has recently been used for the prevention of the migraine attack with considerable success (Sicuteri, 1959; Dalsgaard-Nielsen, 1960; Heyck, 1960; Harris, 1961; Friedman and Losin, 1961; Hale and Reed, 1962; Rooke, Rushton, and Peters, 1962; Ekbom, 1962; Friedman and Elkind, 1963; Graham, 1964). Methysergide, 1-methyl-D-lysergic acid butanolamide, is also known as UML 491, Sansert, or Deseril (Sandoz).

In the past 18 months, 894 new patients have been 
seen at the headache clinic of the Prince Henry Hospital, of whom 465 suffered from migraine. Eighty-seven of these patients were subject to irregular or infrequent attacks and were excluded from the trial. The present series therefore comprises 378 patients suffering regular attacks of migraine at least once a month, 320 of whom have been treated with methysergide. Bilateral headaches were accepted as being migrainous if they were accompanied by other components of the migraine syndrome (Selby and Lance, 1960). Our experiences with methysergide and other preparations are presented in this paper.

\section{ORGANIZATION OF THE TRIAL}

Three hundred and twenty patients (240 females and 80 males) participated in the clinical trial of methysergide. Ninety of these patients were included in a controlled trial, and the improvement obtained with methysergide was found to be statistically highly significant (Lance, Fine, and Curran, 1963). All patients were instructed to report at monthly intervals at first, so that their response could be assessed. Twelve patients did not heed this advice or answer our enquiring letters, and were considered to be unimproved for the purpose of the trial.

The patients' response was classified under four headings: 'virtually headache-free', 'substantially improved' (with half or less than half of the previous frequency of attacks), 'no change', or 'abandoned'. The last category consists of patients who experienced severe sideeffects (either initially or after some months of methysergide therapy), and patients who suffered a relapse while on methysergide. Patients were initially prescribed $6 \mathrm{mg}$. of methysergide daily, and this dosage was gradually reduced in improved patients to the minimal dose that maintained improvement. If patients did not respond to $6 \mathrm{mg}$. methysergide daily, the drug was usually suspended and other treatment instituted, but in a few cases the dosage was increased to $8 \mathrm{mg}$. daily. Patients were reviewed at intervals of two to three months once they were established on a successful régime.

\section{RESULTS}

The effect of methysergide in reducing the frequency of migraine attacks in 320 patients is shown in Table I. Table II summarizes the length of follow-up of the 180 patients who maintained improvement.

Thirty-six of the 63 patients who remained virtually headache-free required a dosage of $6 \mathrm{mg}$. daily, but in 27 cases the dosage was reduced to $4 \mathrm{mg}$. or less daily. In one instance improvement has been maintained for 18 months on $2 \mathrm{mg}$. daily.

Greater difficulty was experienced in reducing the methysergide dosage in the 117 patients who were substantially improved but were not free of headache, as only 19 patients could be maintained on less than $6 \mathrm{mg}$. daily. Ninety-five patients required $6 \mathrm{mg}$. daily for maintenance, and three patients $8 \mathrm{mg}$.
TABLE I

RESULTS OF METHYSERGIDE TREATMENT

Virtually headache-free

Substantially improved

No change

Abandoned

(1) Initial side-effects

(2) Late side-effects

(3) Relapsed

TABLE II

LENGTH OF FOLLOW-UP ON IMPROVED PATIENTS

\begin{tabular}{|c|c|c|c|}
\hline 3 or Less & $4-6$ & $7-12$ & 13 or Mor \\
\hline $\begin{array}{l}17 \\
34\end{array}$ & $\begin{array}{r}9 \\
32\end{array}$ & $\begin{array}{l}15 \\
35\end{array}$ & $\begin{array}{l}22 \\
16\end{array}$ \\
\hline
\end{tabular}

Virtually headache-free Substantially improved

daily. The 11 patients who relapsed after somen months on methysergide therapy had never beeb completely free of headache, i.e., no patient who became headache-free during the first month o $\vec{\omega}$ methysergide therapy has relapsed.

Forty-six patients from the 'substantially im proved' and 'no change' groups were at some time in the course of treatment given a vasodilator drug in addition to their maintenance dose of methysergide: The drugs used were nicotinic acid 50-100 mg. t.d. Ronicol $25-50 \mathrm{mg}$. t.d.s., and Hydergine $0.5 \mathrm{mgg}$ t.d.s., the patient adjusting the dose to prodice facial flushing. It was noted that 17 patients significantly fewer headaches than on methysergide alone and 10 of these 17 patients became freegof headache. Twenty-eight patients were unchanged $\mathrm{m}_{\mathrm{y}}$ the addition of vasodilator substances, and one made worse. In contrast to the result of combineds therapy, of 13 patients given vasodilators alonep none was improved and five became worse.

SIDE-EFFECTS Side-effects of methysergide weren experienced by 140 patients $(45 \%)$ of the 308 pre-D senting for review. The majority of these were mild or transient, and comprised the symptoms outlined by Lance et al. (1963), who found that $12 \%$ of patients given placebo tablets complained of similas mild side-effects. In 32 of our patients $(10 \%)$ the side-effects were of sufficient severity to warrant the discontinuation of methysergide. Thirty-one of these patients were women. The main symptom responsible? for each patient ceasing treatment is listed in Table III.

In all but six patients the side-effects listed above developed on the first or second day of methysergide? therapy, often after only one or two tablets. Two $>$ patients developed intermittent claudication after six and 11 months respectively. A 65-year-oldn woman developed angina pectoris after six months: therapy with methysergide, which is classified as ao 
TABLE III

SEVERE SIDE-EFFECTS OF METHYSERGIDE

\begin{tabular}{l} 
Side-effect \\
\hline Cardiovascular \\
Angina pectoris \\
Intermittent claudication \\
Lower limb pains \\
Upper limb pains \\
Swelling of ankles \\
Venules over nose and cheeks \\
Facial flushing \\
Gastrointestinal \\
Vomiting \\
Abdominal cramps \\
Dermatological \\
Rash \\
Scalp hair falling out \\
Neurological \\
Vertigo and ataxia
\end{tabular}

Number of Patients

side-effect of methysergide but may well be coincidental in view of her pre-existing hypertension. Two patients, both women, noticed that their hair began to fall out excessively when combed after about four months' treatment. A woman, who had been taking methysergide immediately before attending the clinic, also commented on this. Hair ceased to fall out in this patient and the patient recorded in Table III two months after methysergide had been suspended. One patient continued treatment and has since reported that her hair is no longer falling out and that new hair is growing.

A number of patients noticed swelling of the ankles after some months of treatment, but only one stopped taking the drug on this account. One patient developed conspicuous venules over the nose and cheeks after taking methysergide for five months. They disappeared on suspension of the drug, only to recur when methysergide was given again.

Four of our patients who responded well to methysergide but who experienced limb pains or numbness were placed on a vasodilator drug in addition to methysergide. Three patients maintained their improvement and were relieved of side-effects, and one patient remained unchanged. The following is an illustrative case:

A woman aged 59 had suffered approximately eight attacks of right hemicrania monthly for the past five years. After one month on methysergide, $6 \mathrm{mg}$. daily, she was free of headache but complained of weakness and numbness of her left hand. Examination revealed that the left radial pulse was absent and the small muscles of the left hand were weak. Methysergide was suspended and Hydergine substituted. Power returned within two days and the left radial pulse was palpable when she was examined one week later. The patient then experienced second daily right hemicrania for one month. Methysergide and Hydergine in combination restored the patient's freedom from headache without further weakness or numbness of her left hand.
Three patients who suffered severe side-effects initially, necessitating discontinuation of methysergide, resumed taking the drug some months later when all other forms of medication failed. In each instance side-effects were minimal and the drug could be continued.

As well as the 13 patients whose medication was suspended because of pains in the limbs or frank intermittent claudication, another 19 patients complained of some pain in the limbs. Four of these patients were free of headache on methysergide, 11 were improved, and four unchanged.

Some other minor side-effects are worthy of individual comment. Eighteen patients gained $5 \mathrm{lb}$. or more in weight while under treatment. Nine of these were headache-free and seven substantially improved.

A peculiar symptom was mentioned by two male patients, both reliable observers, who stated that several times in the day their thoughts 'would seem to stop for a second'. This symptom, which is suggestive of temporal lobe disturbance, did not distress the patients who wished to continue treatment.

RESPONSE TO METHYSERGIDE THERAPY IN RELATION TO CERTAIN HEADACHE CHARACTERISTICS In an attempt to obtain some criteria of selection for methysergide treatment, the response in relation to certain characteristics of the headache has been analysed in Table IV. In Table IV family history refers only to the patient's parents and siblings.

It can be seen that males responded better than females and that patients in the reproductive period aged 21-40 fared worse than average. The response was better in patients who suffered three or more headaches each month. The association of diarrhoea with the headache and the lack of previous response to any ergotamine preparation are probably indices of the severity of the attack.

RESPONSE TO METHYSERGIDE COMPARED .WITH THAT TO PLACEBO, CYPROHEPTADINE, AND BELLERGAL Cyproheptadine (Periactin) has one fourth the antiserotonin effect of inethysergide and the equivalent dosage of 12 to $24 \mathrm{mg}$. daily has therefore been used in this clinic. Bellergal is a mixture of phenobarbitone, $20 \mathrm{mg}$., ergotamine tartrate, $0.3 \mathrm{mg}$., and belladonna alkaloids, $0 \cdot 1 \mathrm{mg}$., given three times daily, which has been used in the interval treatment of migraine for many years. For the past six months we have prescribed these preparations in order to compare the results obtained with serotonin antagonists, methysergide and cyproheptadine, with the efficacy of the long-standing remedy Bellergal.

In Table $\mathrm{V}$ we have included the response to placebo and to methysergide which were reported by 
TABLE IV

RESPONSE TO METHYSERGIDE IN RELATION TO CHARACTERISTICS OF HEADACHE

\begin{tabular}{|c|c|c|c|}
\hline & & Total & Number Improved \\
\hline $\begin{array}{l}\text { Sex } \\
\text { Age of onset (yr.) }\end{array}$ & $\begin{array}{l}\text { Male } \\
\text { Female } \\
20 \text { or less } \\
21-40 \\
\text { Over } 40\end{array}$ & $\begin{array}{r}80 \\
240 \\
173 \\
122 \\
25\end{array}$ & $\begin{array}{r}55(69 \%) \\
125(52 \%) \\
87(50 \%) \\
77(63 \%) \\
16(64 \%)\end{array}$ \\
\hline Present age & $\begin{array}{l}20 \text { or less } \\
21-40 \\
\text { Over } 40\end{array}$ & $\begin{array}{r}17 \\
119 \\
184\end{array}$ & $\begin{array}{l}14(82 \%) \\
56(47 \%) \\
110(60 \%)\end{array}$ \\
\hline $\begin{array}{l}\text { Headache } \\
\text { Frequency per } \\
\text { month }\end{array}$ & $\begin{array}{l}1-2 \\
3-4 \\
5-8 \\
\text { Over } 8\end{array}$ & $\begin{array}{r}85 \\
121 \\
62 \\
52\end{array}$ & $\begin{array}{l}36(42 \%) \\
70(58 \%) \\
35(55 \%) \\
39(75 \%)\end{array}$ \\
\hline Site of headache & $\begin{array}{l}\text { Hemicrania } \\
\text { Holocrania }\end{array}$ & $\begin{array}{l}217 \\
103\end{array}$ & $\begin{array}{r}124(57 \%) \\
56(54 \%)\end{array}$ \\
\hline $\begin{array}{l}\text { Phenomena } \\
\text { associated } \\
\text { with headache }\end{array}$ & $\begin{array}{l}\text { Polyuria } \\
\text { Vomiting } \\
\text { Diarrhoea } \\
\text { Photopsia, } \\
\text { fortification } \\
\text { spectra, } \\
\text { paraesthesiae } \\
\begin{array}{l}\text { Minor brain-stem } \\
\text { disturbances }\end{array}\end{array}$ & $\begin{array}{r}94 \\
228 \\
65 \\
\\
132 \\
\\
\\
166\end{array}$ & $\begin{array}{r}56(60 \%) \\
125(55 \%) \\
32(49 \%) \\
67(51 \%)\end{array}$ \\
\hline $\begin{array}{l}\text { Response to } \\
\text { Ergotamine }\end{array}$ & $\begin{array}{l}\text { Relieved } \\
\text { Unrelieved } \\
\text { Unknown }\end{array}$ & $\begin{array}{r}126 \\
69 \\
125\end{array}$ & $\begin{array}{l}78(62 \%) \\
33(48 \%)\end{array}$ \\
\hline $\begin{array}{l}\text { Family history } \\
\text { of migraine }\end{array}$ & $\begin{array}{l}\text { Positive } \\
\text { Negative } \\
\text { Unknown }\end{array}$ & $\begin{array}{r}172 \\
138 \\
10\end{array}$ & $\begin{array}{l}94(54 \%) \\
82(60 \%)\end{array}$ \\
\hline
\end{tabular}

TABLE V

COMPARISON OF RESPONSE TO PLACEBO, METHYSERGIDE, CYPROHEPTADINE, AND BELLERGAL AFTER SIX MONTHS' TRIAL

\begin{tabular}{lcccc} 
& Placebo & $\begin{array}{l}\text { Methy- } \\
\text { sergide }\end{array}$ & $\begin{array}{l}\text { Cypro- } \\
\text { heptadine }\end{array}$ & Bellergal \\
\cline { 2 - 5 } $\begin{array}{l}\text { Headache-free } \\
\text { Substantially } \\
\text { improved }\end{array}$ & $1(2 \%)$ & $35(24 \%)$ & $15(15 \%)$ & $18(10 \%)$ \\
No change & $40(80 \%)$ & $41(28 \%)$ & $46(46 \%)$ & $114(66 \%)$ \\
Abandoned & 0 & $13(8 \%)$ & $8(8 \%)$ & 0 \\
Total & 50 & 150 & 100 & 174
\end{tabular}

us (Lance et al., 1963) after six months' experience with methysergide. It is considered that this is a fair basis of comparison, as the response to cyproheptadine and Bellergal was also assessed after a six-month trial period.

The $64 \%$ improvement obtained with methysergide over a six-month period is significantly greater than the $46 \%$ of patients responding to cyproheptadine $(\mathrm{p}=<0.01)$, the $34 \%$ of patients responding to Bellergal $(p=<0.001)$, and the $20 \%$ response to placebo $(\mathrm{p}=<0.001)$.
Side-effects were less common and less severe withe cyproheptadine than with methysergide, although $\bar{z}$ the percentage of those abandoning treatment within: six months was the same. Cyproheptadine was diso continued for the following reasons: drowsiness (three patients), nausea (two patients), vomiting ataxia, paraesthesiae (each, one patient). Eight othere patients complained of side-effects while continuinge treatment, namely, aching legs (three patients) swollen ankles (two patients), weight gain (tw $\vec{Q}$ patients), and diarrhoea (one patient). Many of these symptoms are remarkably similar to those en countered with methysergide.

\section{DISCUSSION}

The response to methysergide reported in this papeen demonstrates its value in the treatment of resistant migraine. It is particularly useful in prophylaxis when attacks are frequent, and $61 \%$ of patient experiencing three or more headaches each montlp showed substantial improvement. We found methy sergide to be less effective in patients who are subject to one or two attacks each month, only $42 \%$ of this group responding to treatment. The improvemenit rate in males $(69 \%)$ was higher than that in fematest $(52 \%)$, partly because the incidence of severe sidee effects was less. Only one male patient had to stop taking methysergide, whereas 31 female patieghts abandoned treatment. The site of the headacke whether habitually unilateral or bilateral, and the presence or absence of cerebral or brain-stem $4 \mathrm{~s}$ turbances at the time of the migraine attack, did alter significantly the response to methysergide. It iq of particular interest that changes in urinary volume or the association of diarrhoea with the migraine attack showed no correlation with improvement rate since it has been postulated that serotonin might be responsible for these symptoms.

Most authors have reported a higher percentage of improvement than ours, and those who have made्ह controlled observations have also noted a greater response to placebo. The probable explanation for this is that patients were referred to us when other. treatment had failed, so that most placebo reactors had been eliminated. Our 'placebo response' woulक्ष therefore approximate to the remissions to be exo pected in the natural history of the disorder. recent paper by Southwell, Williams, and Mackenzie (1964) is the only publication we have seen which casts doubt on the therapeutic value of methysergideo They found that 141 'severe' headaches were ex? perienced by 34 patients while on placebo and 103 while on methysergide, the trial period being six weeks with a 'cross-over' design. This reduction appears unimpressive, but could represent eight of 
their 34 patients becoming headache free and a further nine being 'half improved', a yield of $50 \%$ improvement, as their patients suffered severe headaches at least once a fortnight. Southwell et al. (1964) commented that the effect of methysergide may have continued into the second six-week period, when the patient was taking placebo. We have noted the reverse situation on occasions when patients who have been well-controlled with methysergide suddenly stop medication and experience a 'rebound' recurrence of headache at a frequency greater than that before treatment was started. Graham (1964) also commented on this.

Side-effects were frequent. Many of the transient disturbances such as nausea became less of a problem when patients started with one tablet $(1 \mathrm{mg}$.) after meals, and then increased to $2 \mathrm{mg}$. three times daily after a few days. When the patient was established on the full dosage, the timing was altered so that the first dose was taken on waking and the last on retiring.

The most troublesome side-effects were those presumably caused by vasoconstriction. Methysergide is said not to alter the peripheral circulation in animals (Friedman, 1960) and does not constrict the conjunctival blood vessels in man, although it potentiates the effect of norepinephrine (Dalessio, Camp, Goodell, and Wolff, 1961).

Definite evidence of constriction of a major artery was obtained in one patient who was taking methysergide on our advice while living in New Guinea, but who was not under our direct care. This patient had been taking $6 \mathrm{mg}$. methysergide daily for four months when she noticed pain in the right arm immediately before departing by air for London. On arrival in London she was admitted to University College Hospital under the care of Professor M. Rosenheim. Pulses in the right arm below the axillary artery were impalpable. Surgical exploration, performed after angiographic confirmation of an obstructed brachial artery, showed that the vessel was reddened and in spasm. She made a complete recovery after cessation of methysergide.

Fifteen of our patients had to cease treatment because of symptoms suggesting vasoconstriction, and 19 patients experienced a lesser degree of pain in the limbs, often after taking only one or two tablets. The addition of a vasodilator drug relieved the symptom in some instances, without nullifying the beneficial effect of methysergide on the patients' headache. Indeed a further increment of improvement was observed in 17 of 46 patients treated with a combination of vasodilator drug and methysergide. The only episode in our series which was alarming was the experience of a woman, aged 21 years, who developed tightness of the chest with aching in the left arm, dyspnoea, and palpitations after taking one tablet. This was almost certainly caused by coronary vasoconstriction, which fortunately appears to be a rare reaction to the drug.

Graham (1964) has reported two patients with 'retroperitoneal fibrosis' following phlebitis of the legs. He informed us by letter that these patients presented with ureteric obstruction.

We have advised female patients to cease methysergide should they become pregnant, because the majority of women have a remission of migraine during pregnancy, and because methysergide is chemically very closely related to the ergot alkaloids which have recognized oxytocic effects. Graham (1960) mentioned that one patient, who was five and one half months pregnant, began a threatened abortion 12 hours after taking the second dose of $2 \mathrm{mg}$. of methysergide. One of our patients did not realize that she was pregnant for some months, and so continued treatment with methysergide for the first three and a half months of her pregnancy. She stated it was the best pregnancy of her last three, as one had been associated with a number of threatened miscarriages, and the second terminated in a miscarriage. She gave birth to a healthy girl who is now 4 months old.

It is doubtful whether weight gain should be regarded as a side-effect of methysergide. It may well be a non-specific response to a patient's improved health, since 16 of the 18 patients experiencing weight gain were improved. We have noticed a comparable increase in weight in patients whose headaches have been relieved by drugs other than methysergide. The weight gain usually ceased after two months.

The mechanism of action of methysergide is at present unknown. Dalessio et al. (1961) have suggested that methysergide exerts its effect in two ways: centrally by modulating vasomotor functions, and peripherally by potentiating the vasoconstrictor responses of the cranial blood vessels to catecholamines. Dalessio (1962) has shown that methysergide inhibits a number of vasomotor reflexes, e.g., the pressor response to unilateral carotid occlusion and the depressor responses to stimulation of the central end of the cut vagus nerve. Elkind, Friedman, and Grossman (1964), using radioactive sodium to measure the effective skin blood flow, reported that there was no consistent change in skin blood flow after parenteral administration of methysergide, although intravenous noradrenaline and ergotamine tartrate reduced skin blood flow in most patients because of their vasoconstrictor action.

Many of our patients who have become free of headache on methysergide have mentioned that they feel that headaches are present in the background at 
times but do not develop or cause pain. It is possible that they are attempting to describe the sensation of vascular dilatation divorced from its usual painful accompaniment. Some of our patients who in the past had noticed unilateral dilatation of the temporal vessels accompanying migraine, still noticed this in the absence of headache on occasion while taking methysergide. Two patients whose headache was precipitated by exertion found that they were still aware of pulsation of the scalp vessels on exercise but that their customary headache did not follow. One patient who suffered severe second daily right hemicrania which was accompanied by a right-sided Horner's syndrome in a manner similar to Horton's 'histaminic cephalalgia', was admitted to hospital. The patient became free of headache when methysergide was administered, but a transient Horner's syndrome was observed on several occasions during her stay in hospital.

These observations suggest that methysergide is either reducing the degree of vascular dilatation to the point where it is no longer painful, or blocking the action of some pain-producing substance peripherally. There is no indication that methysergide depends for its action on sustaining constriction of cranial vessels; in fact vasodilator drugs appear to enhance the efficacy of methysergide rather than reduce it. Most of the patients who suffered vasoconstriction as a side-effect were relieved of migraine, although four such patients continued to have attacks at their previous frequency. Vasoconstrictor symptoms were often asymmetrical, often occurred after small doses of methysergide, and affected a comparatively small number of patients in the series, making it unlikely that this effect is the property of methysergide essential for the control of migraine.

Methysergide has proved of great benefit in reducing the frequency and severity of migraine attacks. Because of the nature of side-effects, it is advisable for any patient to remain under medical supervision for the duration of treatment, which will probably have to be continued as long as the tendency to migraine persists. Bellergal and cyproheptadine have fewer and milder side-effects than methysergide, and are therefore worth a trial first so that methysergide may be reserved for unresponsive patients.

\section{SUMMARY}

A lysergic acid derivative, methysergide (Deseril), has been subjected to clinical trial in a series of 320 patients suffering one or more severe migraine attacks each month. Sixty-three patients $(20 \%)$ became virtually free of headache, and a further 117 $(36 \%)$ were substantially improved over a follow up period extending to 18 months. Results were bette in patients experiencing three or more headaches each month.

Side-effects were experienced by $45 \%$ of patient but these were mostly mild and/or transient. Hove ever, methysergide had to be discontinued in 32 patients $(10 \%), 17$ of whom experienced vasocons strictive phenomena. Thirty-one of these patients were women.

Methysergide proved more effective in the proph疋 laxis of migraine than another serotonin antagonist: cyproheptadine, and the long-used preparation Bellergal.

It is concluded that methysergide is both effective and useful in the prevention of frequent migraine attacks. The importance of the patient remainin 8 under strict medical supervision is emphasized.

We wish to express our appreciation to Dr. R. D. Fine $\vec{\circ}$ Dr. G. Preswick, Dr. G. Vakkur, and Dr. D. Brender, who have assisted in the work of the headache clinic, anf also to Miss A. M. Mackie, Miss H. Baker, and the stafof the Pharmacy Department. We acknowledge wit thanks the support of Merck, Sharp, and Dohme (Austido Pty. Ltd., and Sandoz (Aust.) Pty. Ltd., who provided్ drugs for clinical trial without charge.

\section{REFERENCES}

Bickerstaff, E. R. (1961a). Lancet, 1, 15.

(1961b). Ibid., 2, 1057.

Chapman, L. F.. Ramos, A. O., Goodell, H., Silverman, G Wolff, H. G. (1960). Arch. Neurol., 3, 223.

Dalessio, D. J. (1962). J. Amer. med. Ass., 181, 318.

- Camp, W. A. Goodell, H., and Wolff, H. G. (1961). Neurol., 4, 235.

Dalsgaard-Nielsen, T. (1960). Praxis, 49, 867.

Ekbom, K. A. (1962). Acta neurol. scand., 38, 313.

Elkind, A. H., Friedman, A. P., and Grossman, J. (1964). Neurology (Minneap.), 14, 24.

Friedman, A. P. (1955). Ibid., 5, 805.

(1960). Angiology, 11, 364.

and Elkind, A. H. (1963). J. Amer. med. Ass., 184, 125.

and Losin, S. (1961). Arch. Neurol., 4, 241.

Graham, J. R. (1960). New Engl. J. Med., 263, 1273.

(1964). Ibid., 270, 67.

Hale, A. R., and Reed, A. F. (1962). Amer. J. med. Sci., 243, 92.

Harris, M. C. (1961). Ann. Allergy, 19, 500.

Haverback. B. J., Dutcher, T. F., Shore, P. A., Tomich, E. G Terry, L. L., and Brodie, B. B. (1957). New Engl. J. Med. 256, 343.

Heyck, H. von. (1960). Schweiz. med. Wschr., 90, 203.

Kimball, R. W., Friedman, A. P., and Vallejo, E. (1960). Neurology (Minneap.), 10, 107.

Lance, J. W., Fine, R. D., and Curran, D. A. (1963). Med. J. Aust $1,814$.

Lund, F. (1957). Acta med. scand., 158, 21.

Ostfeld, A. M., Chapman, L. F., Goodell, H., and Wolf, H. G. (1957).

Psychosom. Med., 19, 199.
_, Reis, D. J., Goodell, H., and Wolff, H. G. (1955). Arch. intern Med., 96, 142. Rooke, E. D., Rushton, J. G., and Peters, G. A. (1962). Proc. May@
Clin., 37, 433 .

Schottstaedt, W. W., and Wolff, H. G. (1955). A.M.A. Arch. NeuroD Psychiat., 73, 158.

Selby, G., and Lance, J. W. (1960). J. Neurol. Neurosurg. Psychiat., 23, 23.

Sicuteri, F. (1959). Int. Arch. Allergy. 15, 300.

—, Testi, A., and Anselmi, B. (1961). Ibid., 19, 55.

$$
\text { 每 }
$$
. 
Southren, A. L., and Christoff, N. (1962). J. Lab. clin. Med., 59, 320. Southwell, N., Williams, J. D., and Mackenzie, I. (1964). Lancet, 1, 523.

Tunis, M. M., and Wolff, H. G. (1952). Amer. J. med. Sci., 224, 565. Wolff, H. G. (1955). Int. Arch. Allergy., 7, 210.

\section{ADDENDUM}

Since this paper was submitted for publication the authors, in collaboration with Dr. H. Hinterberger, have completed an investigation yielding further information about the relation of serotonin to migraine, and a possible mechanism of action of methysergide. Four-hourly estimation of urinary 5HIAA before, during, and after 31 migraine headaches has demonstrated a sudden increase in 5HIAA excretion (approximately two-fold) in the first 12 hours of the attack, irrespective of the presence or absence of vomiting.

Serial total blood serotonin levels showed values below the resting level in $90 \%$ of migraine attacks. In six patients blood samples were taken fortuitously a few hours before the onset of an attack. Blood taken shortly after the onset of the headache revealed that the total blood serotonin level had fallen precipitously in five of these patients and slightly in the sixth.

The administration of methysergide was consistently accompanied by an increase in 5HIAA excretion comparable to that observed in the migraine attack, without any drop in the total blood serotonin levels, suggesting that the antagonism of methysergide to serotonin may be competitive. 